\title{
Prediction of Phase Diagrams in Nano-sized Binary Alloys
}

\author{
Toshihiro Tanaka
}

\author{
Division of Materials and Manufacturing, Graduate School of Engineering, \\ Osaka University, 2-1 Yamadaoka, Suita, Osaka 565-0871, Japan. \\ E-mail: tanaka@mat.eng.osaka-u.ac.jp
}

Keywords: Nano particles, Phase Diagrams, Binary Alloys, Thermodynamics, Surface Tension

\begin{abstract}
The authors have evaluated the surface properties as well as phase diagrams of alloys on the basis of thermodynamic databases. Extending these techniques, we developed a new system to estimate phase equilibria of metals and alloys in small particle systems. The present paper describes our trial to evaluate the phase diagrams of binary alloys in nano-sized particle systems through thermodynamic databases.
\end{abstract}

\section{Introduction}

Various thermodynamic databases have been compiled to be mainly applied to the calculation of phase diagrams of alloys, salts and oxides [1]. The accumulation and assessment of thermodynamic data and phase equilibria information to establish those databases is sometimes called CALPHAD (Computer Calculation of Phase Diagrams) approach [2] in Fig.1.

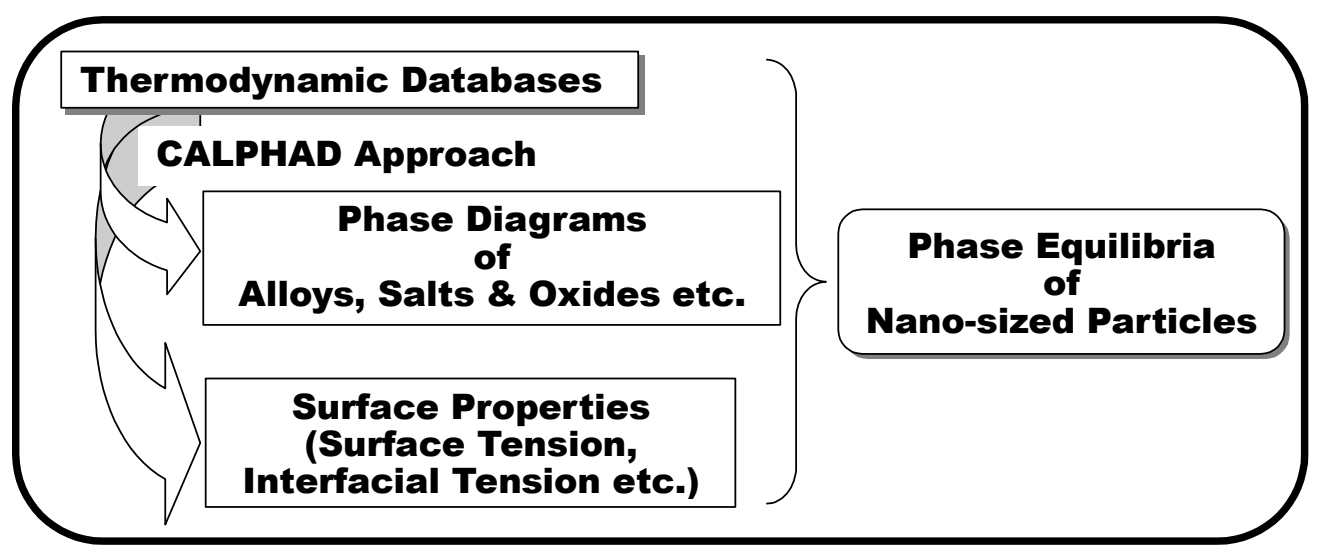

Fig.1. Concept for the prediction of nano-particles alloy phase diagrams.

The CALPHAD approach has been recognized to be useful in various aspects of materials science and engineering [1,2]. If it would be possible to use the thermodynamic databases to evaluate various physico-chemical properties as well as phase diagrams, we could not only widen the applicability of those thermodynamic databases but also further the understanding of the physico-chemical properties. The authors have applied those thermodynamic databases to the evaluation of the surface tension of liquid alloys, molten ionic mixtures, molten slag and the interfacial tension between liquid steel and molten slag [3-17]. These works are aimed to understand the thermodynamic properties of a material system including its surface or interface as well as the bulk. Since the effect of its surface on the total thermodynamic properties can not be negligible in small particles of metals and alloys, the phase relations in these metals and alloys are dependent upon the size of the particle and its surface property. The thermodynamics of solid-liquid phase equilibira in a small particle system was firstly discussed by Pawlow in 1909 [18]. Since Takagi [19] observed that the melting points of some pure metals decrease with decreasing the size of these metallic particles, a lot of studies have been 
carried out on the effect of the particle size on the melting point of pure metals [20-24]. As described above, the authors have evaluated the surface properties as well as phase diagrams of alloys on the basis of thermodynamic databases. Extending these techniques, we have evaluated some phase equilibria of metals and alloys in nano particle systems [25-30]. Hajra and Acharya have reported the calculation of phase diagram in $\mathrm{Cu}-\mathrm{Ag}$ nano-particle alloy [31]. In the present paper, we describe our trial to evaluate the phase diagrams of binary alloys in nano-sized particle systems through thermodynamic databases [25-28].

\section{Thermodynamics in Small Particle Systems.}

Since Pawlow[18] proposed the thermodynamics of small particle system, a lot of work have been done on the effect of the particle size on the melting point of small particles. Although the above analysis by Pawlow[18] was based on the macroscopic thermodynamic point of view, the equation derived by him can be applied to the microscopic melting phenomena of nano-sized particles. According to Pawlow[18] the chemical potentials of pure element $\mathrm{X}$ in liquid and solid small particles with radius r, $\mu_{X}^{\text {Liquid, Particle }}$ and $\mu_{X}^{\text {Solid, Particle }}$, are given in Eqs.(1) and (2):

$$
\begin{aligned}
& \mu_{X}^{\text {Liquid }, \text { Particle }}=\mu_{X}^{\text {Liquid, Bulk }}+\frac{2 \sigma_{X}^{\text {Liquid }} \cdot V_{X}^{\text {Liquid }}}{r} \\
& \mu_{X}^{\text {Solid ,Particle }}=\mu_{X}^{\text {Solid ,Bulk }}+\frac{2 \sigma_{X}^{\text {Solid }} \cdot V_{X}^{\text {Solid }}}{r}
\end{aligned}
$$

where $\mu_{X}^{\text {Liquid,Bulk }}$ and $\mu_{X}^{\text {Solid,Bulk }}$ are chemical potentials of the component $\mathrm{X}$ in liquid and solid phases of the bulk, $\sigma_{X}^{\text {Solid }}$ and $\sigma_{X}^{\text {Liquid }}$ are the surface tensions of pure element $\mathrm{X}$ in solid and liquid phases. $V_{X}^{\text {Solid }}$ and $V_{X}^{\text {Liquid }}$ are the molar volumes of pure element $\mathrm{X}$ in solid and liquid phases.

From the equilibrium condition of liquid and solid phases

$$
\mu_{X}^{\text {Liquid, Particle }}=\mu_{X}^{\text {Solid ,Particle }}
$$

the following equation is obtained:

$$
\mu_{X}^{\text {Liquid ,Bulk }}-\mu_{X}^{\text {Solid ,Bulk }}=\frac{2}{r}\left(\sigma_{X}^{\text {Solid }} \cdot V_{X}^{\text {Solid }}-\sigma_{X}^{\text {Liquid }} \cdot V_{X}^{\text {Liquid }}\right)
$$

Since $\mu_{X}^{\text {Liquid,Bulk }}-\mu_{X}^{\text {Solid,Bulk }}$ is the Gibbs energy change of fusion of the element X, the following approximation can be given:

$$
\mu_{X}^{\text {Liquid }, \text { Bulk }}-\mu_{X}^{\text {Solid }, \text { Bulk }}=\Delta H_{m, X} \cdot\left(1-\frac{T}{T_{m, X}^{\text {Bulk }}}\right)
$$

where $\Delta H_{m, X}$ and $T_{m, X}^{\text {Bulk }}$ are the heat of fusion and the melting point of the element $\mathrm{X}$, respectively. Thus, from Eqs.(4) and (5),

$$
\frac{T}{T_{m, X}^{\text {Bulk }}}=1-\frac{1}{r} \cdot \frac{2}{\Delta H_{m, X}} \cdot\left(\sigma_{X}^{\text {Solid }} \cdot V_{X}^{\text {Solid }}-\sigma_{X}^{\text {Liquid }} \cdot V_{X}^{\text {Liquid }}\right)
$$

The temperature $T$ satisfied with the above equation (6) corresponds to the melting point of the element $\mathrm{X}$ in the small particle system with the radius $\mathrm{r}$. A lot of measurements on the melting of 
small particle metals have been reported so far after Takagi [19] observed the decrease of the melting points of some metallic particles by an electron microscope.

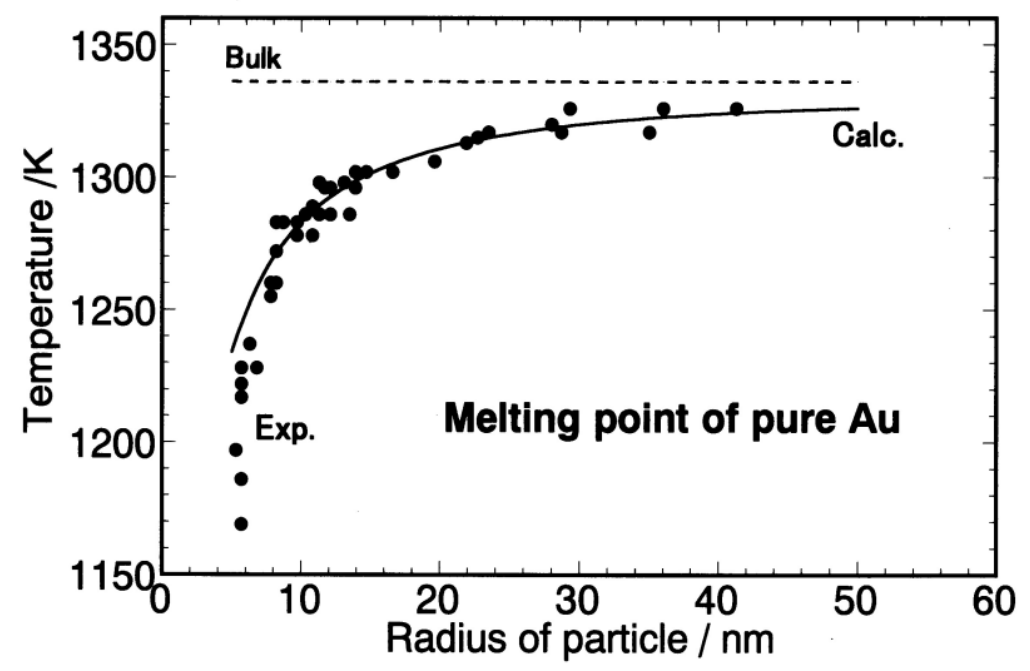

Fig.2. Change in melting point of pure Au with radius of a particle.

For example, Fig. 2 shows the effect of the particle radius on the melting point of Au reported by Coombes [32] and Sambles [33]. The solid curve in this figure indicates the calculated results from the above equation (6). As shown in Fig.2, the calculated results give relatively good agreement with experimental values although the calculated melting point shows larger values than the experimental data for small radius, especially under $5 \mathrm{~nm}$.

On this difference between the calculated melting point and the experimental data, various discussions have been reported, and in addition many improvements have been proposed so far. Borel [34] summarized the thermodynamic investigations [18,21-23,32, 33, 35-40] on the melting of small particles reported hitherto as shown in Table 1.

Table 1. Criteria and Phenomenological models for the melting of nano-sized particles.

\begin{tabular}{|c|c|c|c|}
\hline \multirow[t]{2}{*}{ Criteria of fusion } & \multicolumn{3}{|c|}{ Phenomenological models } \\
\hline & P1(1 phase) & P2(2Phases) & P3(3 Phases) \\
\hline \multirow[t]{5}{*}{$\mathrm{C} 1$ : chemical equilibirium } & & Reiss \& Wilson[35] & Parlow[18] \\
\hline & & Wronsky[21] & Hanzen[36] \\
\hline & & Coombes[32] & Buffat \& Borel[22] \\
\hline & & Sambles[33] & \\
\hline & & $\operatorname{Rie}[37]$ & \\
\hline $\begin{array}{l}\mathrm{C} 2 \text { : liquid phase germination } \\
\text { at the surface }\end{array}$ & & Couchman \& Jesser & 23] \\
\hline $\begin{array}{c}\text { C3 : free energies equality of } \\
\text { solid and liquid } \\
\text { of the same mass }\end{array}$ & \multicolumn{3}{|c|}{ Ross \& Andres[38] } \\
\hline C4 : Lindeman hypothesis & \multicolumn{3}{|c|}{ Couchman \& Ryan[39] } \\
\hline
\end{tabular}

He classified the fusion criteria to some categories as follows:

(C1) Equality of the chemical potentials.

(C2) Germination of the liquid phase at the surface of the solid.

(C3) Equality of the free energy of the solid particle and that of the liquid particle with the same mass. 
(C4) Lindemann hypothesis : the fusion happens when the mean quadratic atomic displacement reaches a certain fraction of the nearest neighbor distance.

In the above list, we adopted only macroscopic thermodynamic approaches although the microscopic researches, for example, molecular dynamics approach etc., were also listed in Borel's original paper [34]. The above each criterion is related to how many phases are considered as shown below:

(P1) One phase model : only the stability of the solid phase is considered.

(P2) Two phase model : a solid phase and a liquid phase are supposed to be in equilibrium.

(P3) Three phase model : the three phases, solid, liquid, vapor are supposed to be in equilibrium(triple point type theory)

Although a lot of work have been done so far as described above, we have not yet reached the completed understanding of the melting of pure metals in small particle systems because we do not have detail information on the atomic structure and the atomic interactions in a nano-sized particle. When the microstructure was analyzed in the nano-sized particles in the above studies, some physical parameters were introduced. For example, in the above (P2) "Two phase model", the liquid phase layer appears around the solid phase core to make the interface between the solid and the liquid phases. This physical description is realistic corresponding to some experimental observations, but the thickness of the liquid layer is an unknown parameter, which we can not determine deductively at the present stage. In the future, the full comprehension may be obtained by combining of the microscopic analysis with the macroscopic thermodynamic approach on the melting of small particles. Although the above studies have been done for mainly pure metals, some investigations on phase transformation in alloys have been reported, of which phase equilibria have not been elucidated enough yet.

The aim of the present paper is to investigate some fundamental issues on the application of thermodynamic databases to the evaluation of phase diagrams of nano-sized particles. Here we select the classical Parlow's criteria for the present trials because his approach can be combined directly with the macroscopic procedure used in the thermodynamic databases without any extra microscopic parameters. In the present paper, we focus on binary alloy phase diagrams in nano-sized particle systems to know how liquidus curves change with the size of the particle, and how the thermodynamic interactions among the components, e.g. activity, excess Gibbs energy etc. affect the phase diagrams in nano particle systems of binary alloys.

\section{Binary Alloy Phase Diagrams of Small Particle Systems consisting of Pure Solid Phases and Liquid Phase.}

At the beginning, we pay attention to some binary alloys, of which phase diagrams consist of liquid phase and pure solid phases such as $\mathrm{Cu}-\mathrm{Pb}, \mathrm{Cu}-\mathrm{Bi}$ and $\mathrm{Au}-\mathrm{Si}$ alloys. In these alloys, their phase diagrams can be evaluated by only the information on the Gibbs energy in the bulk and the surface tension of liquid phase, which can be obtained as functions of temperature and compositions from the thermodynamic databases.

\section{Gibbs Energy of Small Particle Systems.}

If a phase diagram consists of liquid phase and pure solid phases, and in addition, pure solid phase is selected as the reference state of Gibbs energy, the total Gibbs energy of an alloy system in a small particle with its radius $r$ is described in the following equations $(7) \sim(10)$ [40]:

$$
\Delta G^{\text {Total }}=\Delta G^{\text {Bulk }}+\Delta G^{\text {Surface }}
$$

The Gibbs energy of the bulk of A-B binary alloy $\Delta G^{\text {Bulk }}$ in Eq.(1), which corresponds to $\Delta G^{\text {Total }}$ with $r=\infty$, is expressed in Eqs.(8) and (9). 


$$
\begin{aligned}
& \Delta G^{\text {Bulk }}=N_{A} \Delta G_{A}^{L S}+N_{B} \Delta G_{B}^{L S}+G^{\text {Excess }, L}+R T\left(N_{A} \ln N_{A}+N_{B} \ln N_{B}\right) \\
& G^{\text {Excess }, L}=N_{A} N_{B}\left\{L_{0}+L_{1}\left(N_{A}-N_{B}\right)+L_{2}\left(N_{A}-N_{B}\right)^{2}+L_{3}\left(N_{A}-N_{B}\right)^{3}\right\}
\end{aligned}
$$

where $\Delta G_{\mathrm{A}}{ }^{\mathrm{LS}}$ and $\Delta G_{\mathrm{B}}{ }^{\mathrm{LS}}$ are Gibbs energies of pure liquid phases relative to those of pure solid phases, of which temperature dependence are listed in Table $2[41,42] . G^{\text {Excess,L }}$ is the excess Gibbs energy of liquid phase in the A-B alloy. The interaction parameters $L_{\mathrm{i}}(\mathrm{i}=0 \sim 3)$ of $G^{\text {Excess, } \mathrm{L}}$ in Eq.(9) are also listed in Table $3[41,43,44] . N_{\mathrm{A}}$ and $N_{\mathrm{B}}$ are mole fractions of components $\mathrm{A}$ and $\mathrm{B}$.

Table 2. Data of Gibbs energies of pure components

Element $\quad$ Gibbs energies of pure components $/ \mathrm{J} \cdot \mathrm{mol}^{-1}$

$$
\begin{aligned}
& \mathrm{Cu} \quad G_{\mathrm{Cu}}^{\mathrm{L}}=-48.7-(-142.53101) \cdot T+31.380005 \cdot T \cdot(1.0-\ln T) \\
& G_{\mathrm{Cu}} \mathrm{S}=-8044.1-(-110.40401) \cdot T+24.852997 \cdot T \cdot(1.0-\ln T) \\
& -0.0037865 \cdot T^{2} / 2-(-138909) / 2 / T \\
& \Delta G_{\mathrm{Cu}}^{\mathrm{LS}}=G_{\mathrm{Cu}}^{\mathrm{L}}-G_{\mathrm{Cu}} \mathrm{S} \\
& \mathrm{Pb} \quad G_{\mathrm{Pb}}^{\mathrm{L}}=-7347.8-(-133.83501) \cdot T+36.112106 \cdot T \cdot(1.0-\ln T) \\
& -(-0.0097362) \cdot T^{2} / 2-(-279073) / 2 / T-3.2384 \times 10^{-6} \cdot T^{3} / 6 \\
& G_{\mathrm{Pb}} \mathrm{S}=-7608.7-(-75.81465) \cdot T+24.221176 \cdot T \cdot(1.0-\ln \mathrm{T}) \\
& -0.0087111 \cdot T^{2} / 2 \\
& \Delta G_{\mathrm{Pb}}{ }^{\mathrm{LS}}=G_{\mathrm{Pb}}^{\mathrm{L}}-G_{\mathrm{Pb}}^{\mathrm{S}} \\
& \text { Bi } \quad G_{\mathrm{Bi}}^{\mathrm{L}}=7900.3-(-52.22951) \cdot T+23.359299 \cdot T \cdot(1.0-\ln T) \\
& -0.0031380 \cdot T^{2} / 2-1660630 / 2 / \mathrm{T}-\left(-7.1965 \times 10^{-7}\right) \cdot T^{3} / 6 \\
& G_{\mathrm{Bi}}^{\mathrm{S}}=-7817.7-(-100.00800) \cdot T+28.409393 \cdot T \cdot(1.0-\ln T) \\
& -(-0.0246772) T^{2} / 2-5.0 \times 10^{-5} \cdot T^{3} / 6 \\
& \Delta G_{\mathrm{Bi}}{ }^{\mathrm{LS}}=G_{\mathrm{Bi}}^{\mathrm{L}}-G_{\mathrm{Bi}}^{\mathrm{S}} \\
& \mathrm{Au} \quad \Delta G_{\mathrm{Au}}{ }^{\mathrm{LS}}=12552.0-9.385866 \cdot T \\
& \mathrm{Si} \quad \Delta G_{\mathrm{Si}}{ }^{\mathrm{LS}}=50696.36-30.099439 \cdot T+2.0931 \times 10^{-21} \cdot T^{7} \\
& (298.15<T<1687)
\end{aligned}
$$


Table 3 Data of excess Gibbs energy of liquid phase

$$
G^{\text {Excess, } \mathrm{L}}=N_{\mathrm{A}} N_{\mathrm{B}}\left\{L_{0}+L_{1}\left(N_{\mathrm{A}}-N_{\mathrm{B}}\right)+L_{2}\left(N_{\mathrm{A}}-N_{\mathrm{B}}\right)^{2}+L_{3}\left(N_{\mathrm{A}}-N_{\mathrm{B}}\right)^{3}\right\} / \mathrm{J} \cdot \mathrm{mol}^{-1}
$$

$\mathrm{Cu}-\mathrm{Pb}[43]$

$$
\begin{aligned}
& L_{0}=27190.2-4.21329 \cdot T \\
& L_{1}=2229.2-0.53584 \cdot T \\
& L_{2}=-7029.2+6.48832 \cdot T \\
& L_{3}=-7397.6+5.07992 \cdot T
\end{aligned}
$$

$\mathrm{Cu}-\mathrm{Bi}[41]$

$$
\begin{aligned}
& L_{0}=24105.9-9.93287 \cdot T \\
& L_{1}=-2584.5+0.00906 \cdot T
\end{aligned}
$$

Au-Si [44]

$$
\begin{aligned}
& L_{0}=-23863.9-16.23438 \cdot T \\
& L_{1}=-20529.55-6.03958 \cdot T \\
& L_{2}=-8170.5-4.2732 \cdot T \\
& L_{3}=-33138.25+26.56665 \cdot T
\end{aligned}
$$

$\Delta G^{\text {Surface }}$ in Eq.(7), the effect of the surface on $\Delta G^{\text {Total }}$, is assumed as follows [40]:

$$
\Delta G^{\text {Surface }}=\frac{2 \sigma^{L} V^{L}}{r}-\frac{2\left(N_{A} \sigma_{A}^{S} V_{A}^{S}+N_{B} \sigma_{B}^{S} V_{B}^{S}\right)}{r}
$$

where $\sigma^{\mathrm{L}}$ is surface tension of liquid alloy, $V^{\mathrm{L}}$ : molar volume of liquid alloy, $\mathrm{r}$ : radius of a particle, $\sigma_{\mathrm{A}}{ }^{\mathrm{S}}$ and $\sigma_{\mathrm{B}}{ }^{\mathrm{S}}$ : surface tensions of pure solid $\mathrm{A}$ and $\mathrm{B}, V_{\mathrm{A}}{ }^{\mathrm{S}}$ and $V_{\mathrm{B}}{ }^{\mathrm{S}}$ : molar volumes of pure solid $\mathrm{A}$ and B. As shown in Eq.(10), we need the value of the surface tension $\sigma_{X}$ S of pure solid $X$, but the precise information on the value of $\sigma_{X}{ }^{S}$ and its temperature dependence are insufficient [20, 45, 46]. From the data reported in some references[20,45,46], the value of $\sigma_{X} \mathrm{~S}$ of pure solid at the melting point is found to be $25 \%$ larger than the surface tension of pure liquid on the average. Equation (11) is, therefore, assumed to express the surface tension $\sigma_{X}$ s of pure solid $X$ in the present work:

$$
\sigma_{X}^{S}=1.25 \sigma_{X, m p}^{L}+\frac{\partial \sigma_{X}^{L}}{\partial T}\left(T-T_{X, m p}\right) \quad(X=A \text { or } B)
$$

where $\sigma_{\mathrm{X}, \mathrm{mp}}{ }^{\mathrm{L}}$ is the surface tension of pure liquid $\mathrm{X}$ at its melting point $T_{\mathrm{X}, \mathrm{mp}}$.

The temperature dependence of $\sigma_{X}{ }^{S}$ in Eq.(11) is assumed to be the same as that of $\sigma_{X}{ }^{\mathrm{L}}$, which are summarized in Table 4 [47]. In addition, the effects of crystal faces on $\sigma_{X}{ }^{S}$ is ignored in the present work. The molar volume of liquid alloy $V^{\mathrm{L}}$ in Eq.(10) is assumed to be obtained from the following equation:

$$
V^{L}=N_{A} V_{A}^{L}+N_{B} V_{B}^{L}
$$

where $V_{\mathrm{A}}^{\mathrm{L}}$ and $V_{\mathrm{B}}{ }^{\mathrm{L}}$ are molar volumes of pure liquid $\mathrm{A}$ and $\mathrm{B}$. Their temperature dependence are given in Table 4 [47].

The molar volume $V_{\mathrm{X}} \mathrm{S}$ of pure solid $\mathrm{X}$ is evaluated in Eq.(13), which is obtained by considering the volume change due to the fusion at the melting point of each component. 


$$
V_{X}^{S}=\frac{V_{X}^{L}}{\left(1+\alpha_{X}\right)}
$$

where $\alpha_{\mathrm{X}}=\left(V_{\mathrm{X}, \mathrm{m}}{ }^{\mathrm{L}}-V_{\mathrm{X}, \mathrm{m}}{ }^{\mathrm{S}}\right) / V_{\mathrm{X}, \mathrm{m}}{ }^{\mathrm{S}}$, which is the ratio of the volume change of solid due to the fusion, is listed in Table 4 [48]. $V_{\mathrm{X}, \mathrm{m}}^{\mathrm{L}}$ and $V_{\mathrm{X}, \mathrm{m}} \mathrm{s}$ are the molar volumes of pure liquid and solid $\mathrm{X}$ at the melting point.

Table 4 Data of physical properties

$$
\text { Surface tension } \sigma_{\mathrm{X}}^{\mathrm{L}} / \mathrm{Nm}^{-1} \text { of pure liquid components [47] } \quad \frac{\partial \sigma}{\partial T} / \mathrm{Nm}^{-1} \mathrm{~T}^{-1}
$$

\begin{tabular}{llr}
\hline $\mathrm{Cu}$ & $\sigma \mathrm{Cu}^{\mathrm{L}}=1.303-0.00023 \cdot(T-1356.15)$ & -0.00023 \\
$\mathrm{~Pb}$ & $\sigma \mathrm{Lb}=0.458-0.00013 \cdot(T-600.55)$ & -0.00013 \\
$\mathrm{Bi}$ & $\sigma \mathrm{Bi}^{\mathrm{L}}=0.378-0.00007 \cdot(T-544.1)$ & -0.00007 \\
$\mathrm{Au}$ & $\sigma{ }_{\mathrm{Au}}^{\mathrm{L}}=1.169-0.00025 \cdot(T-1336.15)$ & -0.00025 \\
$\mathrm{Si}$ & $\sigma_{\mathrm{Si}}^{\mathrm{L}}=0.865-0.00013 \cdot(T-1687.15)$ & -0.00013 \\
\hline
\end{tabular}

\begin{tabular}{|c|c|c|c|}
\hline $\begin{array}{l}\mathrm{Cu} \\
\mathrm{Pb} \\
\mathrm{Bi} \\
\mathrm{Au} \\
\mathrm{Si}\end{array}$ & $\begin{array}{l}V_{\mathrm{Cu}}^{\mathrm{L}}=7.94 \times 1 \\
V_{\mathrm{Pb}}^{\mathrm{L}}=19.42 \times \\
V_{\mathrm{Bi}}^{\mathrm{L}}=20.80 \times \\
V_{\mathrm{Au}}^{\mathrm{L}}=11.3 \times 1 \\
V_{\mathrm{Si}}^{\mathrm{L}}=11.1 \times 1\end{array}$ & $\begin{array}{l}1.0+0.0001 \cdot(T \\
\{1.0+0.000124 \\
\{1.0+0.000117 \\
1.0+0.000069 \cdot \\
1.0+0.00014 \cdot(T\end{array}$ & $\begin{array}{l}5.15)\} \\
00.5 \\
44.1)\} \\
336.15)\} \\
7.15)\}\end{array}$ \\
\hline & $\sigma$ X,m.p. ${ }^{\mathrm{L}} / \mathrm{Nm}^{-1}[47]$ & $T_{\mathrm{X}, \mathrm{m} . \mathrm{p} .} / \mathrm{K}$ [47] & $\alpha_{\mathrm{X}}=\left(V_{\mathrm{X}, \mathrm{m}}^{\mathrm{L}}-V_{\mathrm{X}, \mathrm{m}}^{\mathrm{s}}\right) / V_{\mathrm{X}, \mathrm{m}}{ }^{\mathrm{s}}[48]$ \\
\hline $\mathrm{Cu}$ & 1.303 & 1356.15 & 0.0396 \\
\hline $\mathrm{Pb}$ & 0.458 & 600.55 & 0.0381 \\
\hline $\mathrm{Bi}$ & 0.378 & 544.1 & -0.0387 \\
\hline $\mathrm{Au}$ & 1.169 & 1336.15 & 0.055 \\
\hline $\mathrm{Si}$ & 0.865 & 1687.15 & -0.095 \\
\hline
\end{tabular}

Molar volume $/ \mathrm{m}^{3} \mathrm{~mol}^{-1}$ of pure liquid components [47]

When we evaluate the composition and the temperature dependence of the surface tension $\sigma^{\mathrm{L}}$ of liquid phase in Eq.(10), we can calculate $\Delta G^{\text {Total }}$ in Eq.(7) of liquid phase from the above equations. As mentioned above, the authors have evaluated the surface tension of liquid A-B binary alloys on the basis of Butler's equation [49] as follows [4-13]:

$$
\sigma^{L}=\sigma_{A}^{L}+\frac{R T}{A_{A}} \ln \frac{N_{A}^{S}}{N_{A}^{B}}+\frac{1}{A_{A}} G_{A}^{E, S}\left(T, N_{B}^{S}\right)-\frac{1}{A_{A}} G_{A}^{E, B}\left(T, N_{B}^{B}\right)
$$

$$
\sigma^{L}=\sigma_{B}^{L}+\frac{R T}{A_{B}} \ln \frac{N_{B}^{S}}{N_{B}^{B}}+\frac{1}{A_{B}} G_{B}^{E, S}\left(T, N_{B}^{S}\right)-\frac{1}{A_{B}} G_{B}^{E, B}\left(T, N_{B}^{B}\right)
$$


In Eqs.(14a) and (14b), $\sigma_{\mathrm{A}}{ }^{\mathrm{L}}$ and ${\sigma_{\mathrm{B}}}^{\mathrm{L}}$ are surface tensions of pure molten components. $N_{\mathrm{B}}{ }^{\mathrm{S}}$ and $N_{\mathrm{B}}{ }^{\mathrm{B}}$ are mole fractions of element $\mathrm{B}$ in the surface and the bulk, respectively. $A_{\mathrm{X}}=L N_{0}{ }^{1 / 3}\left(V_{\mathrm{X}}^{\mathrm{L}}\right)^{2 / 3}\left(N_{0}\right.$ Avogadro number : $\mathrm{X}=\mathrm{A}$ or $\mathrm{B}, L=1.091)$ is molar surface area of pure $\mathrm{X}$, and this is obtained from the molar volume $V_{\mathrm{X}}^{\mathrm{L}} \cdot G_{\mathrm{X}}^{\mathrm{E}, \mathrm{B}}\left(T, N_{\mathrm{B}}{ }^{\mathrm{B}}\right)$ and $G_{\mathrm{X}}{ }^{\mathrm{E}, \mathrm{S}}\left(T, N_{\mathrm{B}}{ }^{\mathrm{S}}\right)$ are partial excess Gibbs energies of component $\mathrm{X}$ in the bulk and the surface, respectively, as functions of $T$ and $N_{\mathrm{B}}{ }^{\mathrm{B}}$ or $N_{\mathrm{B}} \mathrm{S}$.

Since the partial molar excess Gibbs energy of component $\mathrm{X}(\mathrm{X}=\mathrm{A}$ or $\mathrm{B})$ in the bulk $G_{\mathrm{X}}{ }^{\mathrm{E}, \mathrm{B}}\left(T, N_{\mathrm{B}}{ }^{\mathrm{B}}\right)$ in Eqs.(14a) and (14b) can be obtained directly from $G^{\text {Excess,L }}$ in Eq.(9) by using Eqs.(15a) and (15b).

$$
\begin{aligned}
& G_{A}^{E, B}\left(T, N_{B}^{B}\right)=G^{E x c e s s, L}-N_{B} \frac{\partial G^{E x c e s s, L}}{\partial N_{B}} \\
& G_{B}^{E, B}\left(T, N_{B}^{B}\right)=G^{E x c e s s, L}+\left(1-N_{B}\right) \frac{\partial G^{E x c e s s}, L}{\partial N_{B}}
\end{aligned}
$$

For the excess Gibbs energy in the surface, we derived the following equations [4-13] based on the model proposed by Speiser, Yeum et al. [50, 51].

$$
\begin{aligned}
& G_{X}^{E, S}\left(T, N_{B}^{S}\right)=\beta^{M I X} \cdot G_{X}^{E, B}\left(T, N_{B}^{S}\right) \\
& \beta^{M I X}=0.83 \text { : liquid alloys }
\end{aligned}
$$

Equation (16) means that $G_{\mathrm{X}}{ }^{\mathrm{E}, \mathrm{S}}\left(T, N_{\mathrm{B}}{ }^{\mathrm{S}}\right)$, which has the same formula as $G_{\mathrm{X}}{ }^{\mathrm{E}, \mathrm{B}}\left(T, N_{\mathrm{B}}{ }^{\mathrm{B}}\right)$, is obtained by replacing $N_{\mathrm{B}}{ }^{\mathrm{B}}$ by $N_{\mathrm{B}}{ }^{\mathrm{S}}$ in $G_{\mathrm{X}}{ }^{\mathrm{E}, \mathrm{B}}\left(T, N_{\mathrm{B}}{ }^{\mathrm{B}}\right)\left(\mathrm{X}=\mathrm{A}\right.$ or B) and then multiplying $\beta^{\mathrm{MIX}}$ to $G_{\mathrm{X}}{ }^{\mathrm{E}, \mathrm{B}}\left(T, N_{\mathrm{B}}{ }^{\mathrm{S}}\right) \cdot \beta^{\mathrm{MIX}}$ is a parameter corresponding to the ratio of the coordination number in the surface to that in the bulk considering the surface relaxation [4-13].

The surface tension $\sigma^{\mathrm{L}}$ of liquid alloys can be calculated from Eqs.(14) (17) as follows:

1) Setting temperature $\mathrm{T}$ and composition $N_{\mathrm{B}}{ }^{\mathrm{B}}$ of a solution.

2) Inserting the values for surface tension $\sigma_{X}{ }^{L}$ and molar volume $V_{X}$ of pure liquid substances at the above temperature in Eqs. (14a) and (14b).

3) Determining excess Gibbs energies in the bulk phase at the above temperature and composition, and substituting them in Eqs. (14a) and (14b).

4) Then, Eqs.(14a) and (14b) become the simultaneous equations with unknown $N_{\mathrm{B}}^{\mathrm{S}}$ and $\sigma^{\mathrm{L}}$. These equations are solved for those unknown $N_{\mathrm{B}}^{\mathrm{S}}$ and $\sigma^{\mathrm{L}}$ numerically.

From Eqs.(7) (17), the Gibbs energy $\Delta G^{\text {Total }}$ in Eq.(7) of liquid phase relative to pure solid phase, which is selected as the reference state in the present work, can be obtained as a function of $N_{\mathrm{B}}$ at a given temperature. When the liquid phase is equilibrated with pure solid $\mathrm{A}$, the chemical potential of the component A is zero as shown in Fig. 3 because pure solid phase is selected as the reference state. In other words, the liquidus composition $N_{\mathrm{B}}$ at temperature $T$ in Fig. 3 is determined from the composition which satisfies $\mu_{B}{ }^{\mathrm{L}}=0$ on the Gibbs energy curve. When two liquid phases are separated, the liquidus can be determined from the two intersections on a common tangent line with the Gibbs energy curve as shown in Fig.3. 


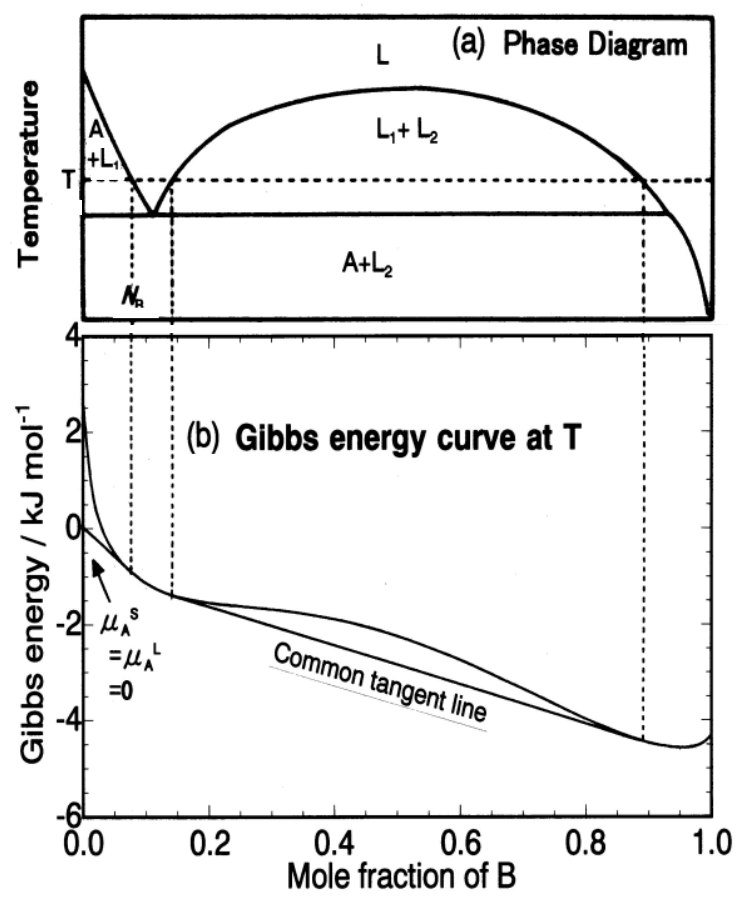

Fig.3. Determination of phase diagram from Gibbs energy curve.

\section{Calculation of Phase Diagrams in Small Particle Systems}

In the present work, we have evaluated the phase diagrams of $\mathrm{Cu}-\mathrm{Pb}, \mathrm{Cu}-\mathrm{Bi}$ and $\mathrm{Au}-\mathrm{Si}$ binary systems, of which phase diagrams consist of liquid phase and pure solid phases. The data which are used for the calculations are summarized in Tables 2-4 [41-44,47,48]. Figs.4(a),(b) and (c) show the calculated results of the surface tension of liquid $\mathrm{Cu}-\mathrm{Pb}, \mathrm{Cu}-\mathrm{Bi}$ and $\mathrm{Au}-\mathrm{Si}$ alloys for a given temperature with activity curves in the bulk of liquid phase.
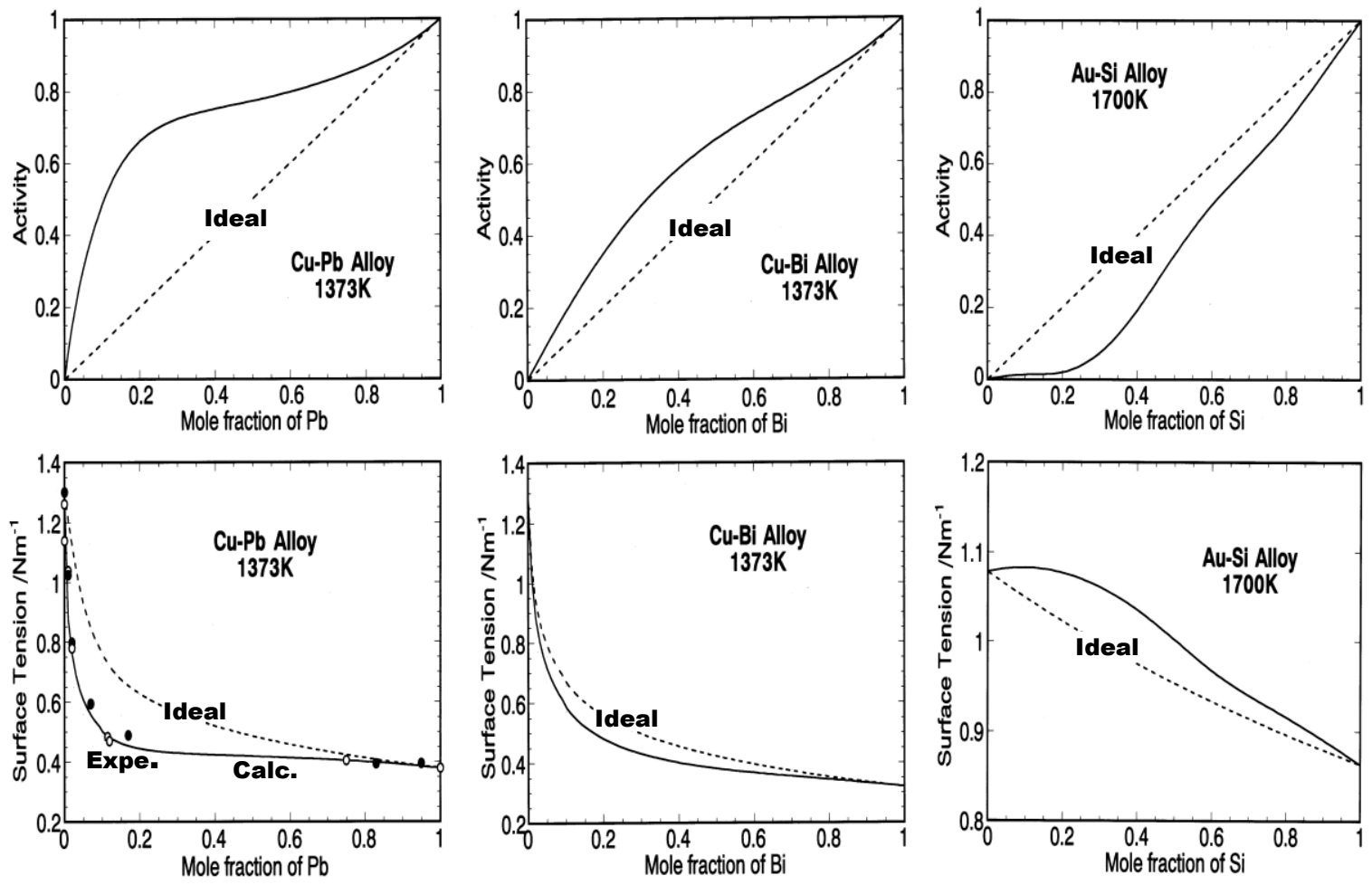

Fig.4. Activities of components in bulk and surface tension of liquid alloys. 
As described in the previous work [4-13], the calculated surface tension of liquid alloys obtained from Eqs.(14) (17) agree well with the experimental results although only $\mathrm{Cu}-\mathrm{Pb}$ alloy in Fig.4(a) shows the comparison of the calculated values with the experimental results $[52,53]$ in the present paper. It is well known that when the alloy, such as $\mathrm{Cu}-\mathrm{Pb}$ or $\mathrm{Cu}-\mathrm{Bi}$ systems, has the large difference between $\sigma_{A}{ }^{\mathrm{L}}$ and $\sigma_{B}{ }^{\mathrm{L}}$ of pure liquid components, the composition dependence of $\sigma^{\mathrm{L}}$ shows large downward deviation from the linearity of $\sigma_{A}{ }^{\mathrm{L}}$ and ${\sigma_{B}}_{B}{ }^{\mathrm{L}}$. In addition, we found from these calculations that in alloys with positive deviation of activity from ideal solution in the bulk $(\mathrm{Cu}-\mathrm{Pb} \& \mathrm{Cu}-\mathrm{Bi}$ alloys), the surface tension deviates negatively from ideal solution. On the other hand, in alloys with negative deviation of activity from ideal solution in the bulk (Au-Si alloy), the surface tension has the tendency to show the positive deviation from ideal solution. Thus, as shown in Figs.4(a),(b) and (c), $\mathrm{Cu}-\mathrm{Pb}$ and $\mathrm{Cu}-\mathrm{Bi}$ liquid alloys indicate the large downward curvature of the composition dependence of the surface tension. On the other hand, in Au-Si alloy, the surface tension of liquid phase changes smoothly with the composition.

From Eqs.(7) (10), the Gibbs energy of pure component $\mathrm{X}$ including the surface is obtained as follows:

$$
\begin{aligned}
\Delta G^{\text {Total }} & =\Delta G^{\text {Bulk }}+\Delta G^{\text {Surface }} \\
& =\Delta G_{X}^{L S}+\frac{2}{r} \cdot\left(\sigma_{X}^{L} \cdot V_{X}^{L}-\sigma_{X}^{S} \cdot V_{X}^{S}\right) \\
& =\Delta G_{X}^{L S}+\frac{2}{r} \cdot\left[\sigma_{X}^{L} \cdot V_{X}^{L}-\left\{1.25 \sigma_{X, m p}+\frac{\partial \sigma_{X}^{L}}{\partial T}\left(T-T_{X, m p}\right)\right\} \cdot \frac{V_{X}^{L}}{1+\alpha_{X}}\right]
\end{aligned}
$$

The temperature $T$ which gives $\Delta G^{\text {Total }}=0$ in Eq.(18) is the melting point of pure $\mathrm{X}$ at a given radius $r$ of a particle. Figs. $1 \& 5$ (a)-(d) show the change in the melting point of pure $\mathrm{Au}, \mathrm{Pb}, \mathrm{Cu}, \mathrm{Bi}$ and $\mathrm{Si}$ with the radius of the particle calculated from Eq.(18).
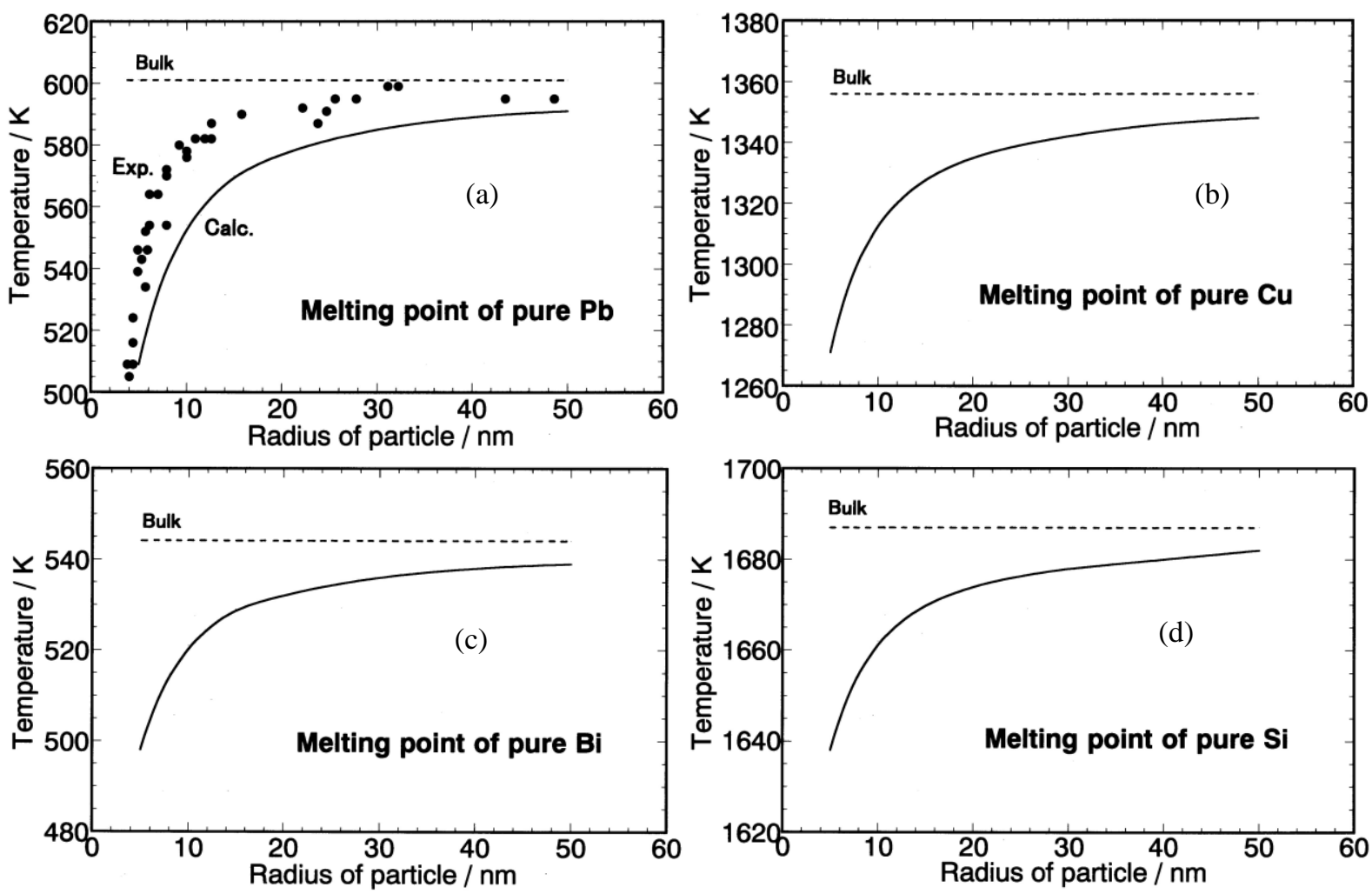

Fig.5. Change in melting points of $\mathrm{Pb}, \mathrm{Cu}, \mathrm{Bi}$ and $\mathrm{Si}$ with radius of a particle. 
Figs.6(a),(b) and (c) show the phase diagrams of $\mathrm{Cu}-\mathrm{Pb}, \mathrm{Cu}-\mathrm{Bi}$ and $\mathrm{Au}-\mathrm{Si}$ alloys for $\mathrm{r}=20 \mathrm{~nm}, 10 \mathrm{~nm}$ and $5 \mathrm{~nm}$ as well as the bulk. Since it has been reported that the value of the surface tension $\sigma^{\mathrm{L}}, \sigma_{\mathrm{X}}{ }^{\mathrm{L}}$, etc. is influenced by the curvature of the surface in a small particle below $r=5 \mathrm{~nm}$ [54-56], the present approach can not be extended to the evaluation of the phase diagrams in the small particle systems with $\mathrm{r}<5 \mathrm{~nm}$. From these results, we found that

1) Liquid phase region in the phase diagrams is enlarged as the size of the particle becomes smaller.

2) Two liquid phases separation region spreads as the size of the particle becomes smaller.

3) In alloys, of which composition dependence of the surface tension of liquid phase shows large downward curvature, such as $\mathrm{Cu}-\mathrm{Pb}$ and $\mathrm{Cu}-\mathrm{Bi}$ alloys, the size of the particle influences largely on the phase relations. On the other hand, in Au-Si alloy, of which surface tension of liquid phase changes smoothly with the composition, the effect of the size on the phase relations is not so large.
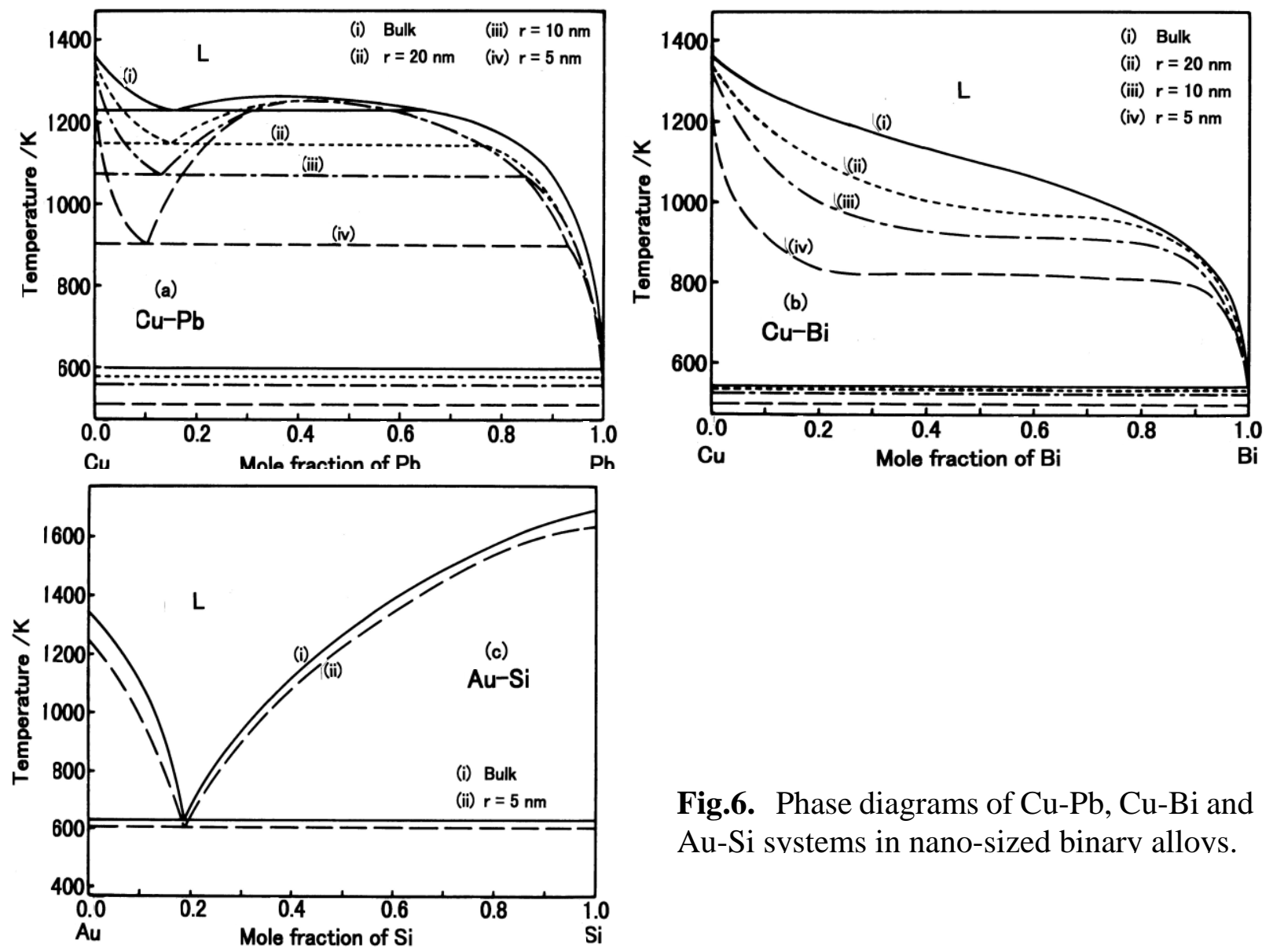

Fig.6. Phase diagrams of $\mathrm{Cu}-\mathrm{Pb}, \mathrm{Cu}-\mathrm{Bi}$ and Au-Si systems in nano-sized binary allovs.

\section{Binary Alloy Phase Diagrams with Solid Solutions in Small Particle Systems.}

In the preceding sections, we focused on some binary alloys, of which phase diagrams consist of liquid phase and pure solid phases, and the solid solutions have not been considered yet. We, however, need to make clear the effect of the excess Gibbs energy on the nano-particle binary phase diagrams including solid solutions more deeply. The purpose of this section is to examine the effect of the excess Gibbs energy in both liquid and solid phases on the nano-particle binary alloy phase diagrams on the basis of the regular solution model. 


\section{Gibbs Energy in Small Particle Systems.}

When a pure solid phase is selected as the reference state of Gibbs energy, the total Gibbs energies in liquid and solid phases, $\Delta G^{\text {Total,Liq }}$ and $\Delta G^{\text {Total,Sol }}$, of an alloy system in a small particle with its radius $\mathrm{r}$ are described in the following equations (19) (24) [25-27]:

$$
\begin{aligned}
& \Delta G^{\text {Total Liq }}=\Delta G^{\text {Bulk,Liq }}+\Delta G^{\text {Surface,Liq }} \\
& \Delta G^{\text {Total,Sol }}=\Delta G^{\text {Bulk,Sol }}+\Delta G^{\text {Surface,Sol }}
\end{aligned}
$$

The Gibbs energy of the bulk of A-B binary alloy in liquid and solid phases, $\Delta G^{\text {Bulk,Liq }}$ and $\Delta G^{\text {Bulk,Sol }}$ in Eqs.(19) and (20), which corresponds to $\Delta G^{\text {Total,P }}(\mathrm{P}=$ Liq or Sol) with $\mathrm{r}=\infty$, are expressed in Eqs.(21) and (22).

$$
\begin{aligned}
& \Delta G^{\text {Bulk,Liq }}=N_{A} \Delta G_{A}^{L S}+N_{B} \Delta G_{B}^{L S}+G^{E x c e s s, L i q}+R T\left(N_{A} \ln N_{A}+N_{B} \ln N_{B}\right) \\
& \Delta G^{\text {Bulk ,Sol }}=G^{\text {Excess ,Sol }}+R T\left(N_{A} \ln N_{A}+N_{B} \ln N_{B}\right)
\end{aligned}
$$

where $\Delta G_{\mathrm{A}}{ }^{\mathrm{LS}}$ and $\Delta G_{\mathrm{B}}{ }^{\mathrm{LS}}$ are Gibbs energies of pure liquid phases relative to those of pure solid phases, in other words, the Gibbs energy of the melting. $G^{\text {Excess,L }}$ and $G^{\text {Excess,Sol }}$ are the excess Gibbs energies of liquid and solid phases in the A-B alloy. $N_{\mathrm{A}}$ and $N_{\mathrm{B}}$ are mole fractions of components A and B. $\Delta G^{\text {Surface,Liq }}$ and $\Delta G^{\text {Surface,Sol }}$ in Eqs.(19) and (20), the effect of the surface on $\Delta G^{\text {Total,P }}$, are assumed as follows [25-27]:

$$
\begin{aligned}
\Delta G^{\text {Surface, Liq }} & =\frac{2 \sigma^{\text {Liq }} V^{\text {Liq }}}{r}-\frac{2\left(N_{A} \sigma_{A}^{\text {Sol }} V_{A}^{\text {Sol }}+N_{B} \sigma_{B}^{\text {Sol }} V_{B}^{\text {Sol }}\right)}{r} \\
\Delta G^{\text {Surface, Sol }} & =\frac{2 \sigma^{\text {Sol }} V^{\text {Sol }}}{r}-\frac{2\left(N_{A} \sigma_{A}^{\text {Sol }} V_{A}^{\text {Sol }}+N_{B} \sigma_{B}^{\text {Sol }} V_{B}^{\text {Sol }}\right)}{r}
\end{aligned}
$$

where the symbols are explained just below in Eq.(10) but here we consider the surface tension of solid alloy $\sigma^{\text {Sol }}$

In order to evaluate the excess Gibbs energy, the regular solution model is applied in the present work because various interaction energies can be selected easily as follows :

$$
\begin{aligned}
& G^{\text {Excess, Liq }}=N_{A} N_{B} W_{A B}^{\text {Liquid }} \\
& G^{\text {Excess, Sol }}=N_{A} N_{B} W_{A B}^{\text {Solid }}
\end{aligned}
$$

where $W_{A B}^{\text {Liquid }}$ and $W_{A B}{ }^{\text {Solid }}$ are the interaction energies in liquid and solid phases.

Since Pelton and Thompson [57] assumed the simple equation on the Gibbs energy of the melting in their evaluation of phase diagrams in Ref. [57], we also use the following equations as they applied.

$$
\begin{aligned}
& \Delta G_{A}^{L S}=T_{A, m p} \cdot S_{A, m p}-T \cdot S_{A, m p} \\
& \Delta G_{B}^{L S}=T_{B, m p} \cdot S_{B, m p}-T \cdot S_{B, m p}
\end{aligned}
$$


where $T_{\mathrm{X}, \mathrm{mp}}$ and $S_{\mathrm{X}, \mathrm{mp}}$ are the melting point and the entropy of fusion for pure substance $\mathrm{X}$ (X=A or B). In the present work, $S_{\mathrm{X}, \mathrm{mp}}$ is roughly assumed to be $10 \mathrm{~J} \cdot \mathrm{K}^{-1} \mathrm{~mol}^{-1}$ according to Richard's rule [46]. In addition, we select here $T_{\mathrm{A}, \mathrm{mp}}=1200 \mathrm{~K}$ and $T_{\mathrm{B}, \mathrm{mp}}=600 \mathrm{~K}$.

On the surface tension of pure liquid metals at their melting points, the following approximation has been reported [47] :

$$
\sigma_{X, m p}^{L i q}\left(N m^{-1}\right)=4.8 \times 10^{-8} R \frac{T_{X, m p}(K)}{\left\{V_{X, m p}\left(m^{3} m o l^{-1}\right)\right\}^{\frac{2}{3}}}
$$

where $\sigma_{\mathrm{X}, \mathrm{mp}}{ }^{\mathrm{Liq}}$ and $V_{\mathrm{X}, \mathrm{mp}}$ are the surface tension and the molar volume of the element $\mathrm{X}$ at its melting point. $R$ is the gas constant, $8.314 \mathrm{JK}^{-1} \mathrm{~mol}^{-1}$.

When we select $V_{\mathrm{X}, \mathrm{mp}}=10 \times 10^{-6} \mathrm{~m}^{3} \mathrm{~mol}^{-1}$, as described below, the following rough relation is obtained from Eq.(29):

$$
\sigma_{X, m p}^{L i q} \fallingdotseq \frac{T_{X, m p}}{1000}\left(\mathrm{Nm}^{-1}\right)
$$

In addition, the temperature coefficient of the surface tension of pure liquid has been reported to be about $0.0001 \mathrm{Nm}^{-1} \mathrm{~K}^{-1}$ [47]. Thus, we assumed the following equation for $\sigma_{\mathrm{A}}{ }^{\mathrm{Liq}}$ and $\sigma_{\mathrm{B}}{ }^{\mathrm{Liq}}$ in the present work.

$$
\begin{gathered}
\sigma_{A}^{L i q}=1.2-0.0001 \cdot\left(T-T_{A, m p}\right) / N^{-1} \quad\left(T_{A, m p}=1200 \mathrm{~K}\right) \\
\sigma_{B}^{L i q}=0.6-0.0001 \cdot\left(T-T_{B, m p}\right) / N^{-1} \quad\left(T_{B, m p}=600 \mathrm{~K}\right)
\end{gathered}
$$

When the preceding equation (11) can be applied for the surface tension $\sigma_{X}$ Sol of pure solid $X$, the following relations are obtained from Eqs.(11), (31) and (32):

$$
\begin{gathered}
\sigma_{A}^{\text {Sol }}=1.25 \times 1.2-0.0001 \cdot\left(T-T_{A, m p}\right) \quad / \mathrm{Nm}^{-1} \\
\sigma_{B}^{\text {Sol }}=1.25 \times 0.6-0.0001 \cdot\left(T-T_{B, m p}\right) \quad / \mathrm{Nm}^{-1}
\end{gathered}
$$

On the molar volume, we used the following values by assuming that the temperature dependence of the molar volume and the volume change due to the melting are neglected because the effect of the excess Gibbs energy and the surface tension on the phase equilibria is focused in the present work.

$$
\begin{aligned}
& V_{A}^{\text {Liq }}=V_{B}^{\text {Liq }}=10 \times 10^{-6} \quad / \mathrm{m}^{3} \mathrm{~mol}^{-1} \\
& V_{A}^{\text {Sol }}=V_{B}^{\text {Sol }}=10 \times 10^{-6} \quad / \mathrm{m}^{3} \mathrm{~mol}^{-1}
\end{aligned}
$$

It is assumed that the molar volumes of liquid alloy $V^{\mathrm{Liq}}$ and solid alloy $V^{\mathrm{Sol}}$ in Eqs.(23) and (24) are obtained from the following simple additivities:

$$
\begin{aligned}
& V^{\text {Liq }}=N_{A} V_{A}^{\text {Liq }}+N_{B} V_{B}^{\text {Liq }} \\
& V^{\text {Sol }}=N_{A} V_{A}^{\text {Sol }}+N_{B} V_{B}^{\text {Sol }}
\end{aligned}
$$


Although the surface tension of liquid and solid alloy $\sigma^{\mathrm{P}}(\mathrm{P}=\mathrm{Liq}$ or Sol) are evaluated from Butler's equation [49] in Eq.(14) as mentioned above, the excess Gibbs energy in the surface for liquid and solid solutions are obtained form the following equations (39)-(41).

$$
\begin{aligned}
& G_{X}^{E, P, \text { Surf }}\left(T, N_{B}^{\text {Surf }}\right)=\beta^{M I X} \cdot G_{X}^{E, P, B u l k}\left(T, N_{B}^{\text {Surf }}\right) \\
& \beta^{M I X}=0.83: \text { liquid alloys } \\
& \beta^{M I X}=\frac{9}{12}=0.75: \text { solid solutions }
\end{aligned}
$$

In particular, for the solid solutions, we assume the value in Eq.(41) as $\beta^{\mathrm{MIX}}$ by assuming the closed-packed structure in the present work because the coordination number in the bulk is 12 and that in the surface is 9 :

\section{Calculated Results of the nano-sized phase diagrams with solid solutions.}

Liquid -solid phase equilibria are obtained from the following thermodynamic conditions :

$$
\begin{aligned}
& \mu_{A}^{\text {Total }, \text { Liq }}=\mu_{A}^{\text {Total }, \text { Sol }} \\
& \mu_{B}^{\text {Total }, \text { Liq }}=\mu_{B}^{\text {Total }, \text { Sol }} \\
& \mu_{A}^{\text {Total }, P}=\Delta G^{\text {Total }, P}-N_{B} \frac{\partial \Delta G^{\text {Total }, P}}{\partial N_{B}} \quad(P=\text { Liq or Sol }) \\
& \mu_{B}^{\text {Total }, P}=\Delta G^{\text {Total }, P}+\left(1-N_{B}\right) \frac{\partial \Delta G^{\text {Total }, P}}{\partial N_{B}} \quad(P=\text { Liq or Sol })
\end{aligned}
$$

\begin{tabular}{|c|c|c|c|c|c|}
\hline & \multicolumn{4}{|c|}{$W_{\mathrm{AB}}^{\text {Solid }} / \mathrm{kJ}$} \\
\hline & & 30 & 15 & 0 & -15 \\
\hline \multirow{4}{*}{$\begin{array}{l}W_{\mathrm{AB}}^{\text {Liquid }} \\
/ \mathrm{kJ}\end{array}$} & 20 & Fig.8(a) & & & \\
\hline & 10 & Fig.8(b) & & & \\
\hline & 0 & Fig.7(c) \&Fig.8(c) & Fig.7(b) & Fig.7(a) & \\
\hline & -20 & Fig.8(d) & & & Fig.7(d) \\
\hline
\end{tabular}

Table 5: Interaction energies of $W_{A B}^{\text {Liquid }}$ and $W_{A B}^{\text {Solid }}$ used in the calculation of phase diagrams.

Figs.7(a)-(d) show the calculated results of the phase diagrams by using the interaction energies in Table 5. In these figures, the solid curves indicates the phase equilibria in the bulk $(r=\infty)$. On the other hand, the chain and the dotted curves are the calculated results for $\mathrm{r}=10 \mathrm{~nm}$ and $5 \mathrm{~nm}$, respectively. 
(a)

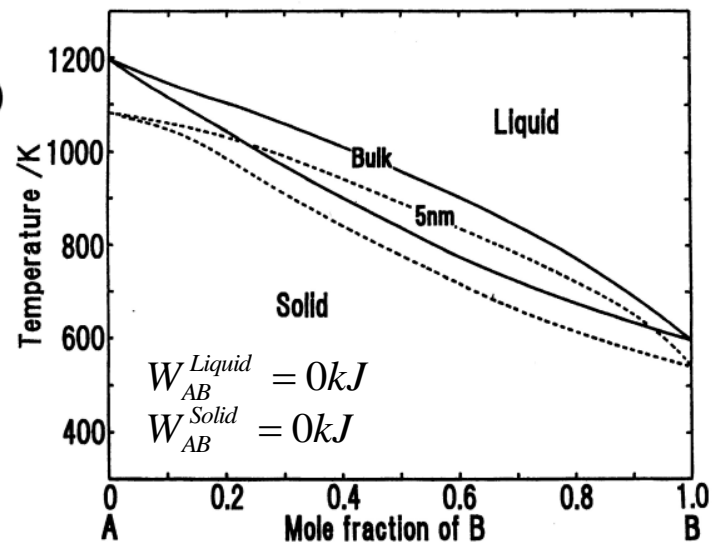

(b)

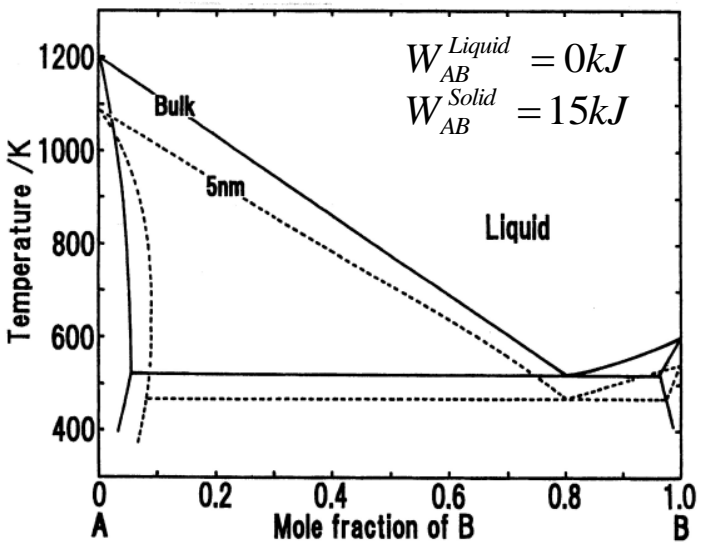

(c)

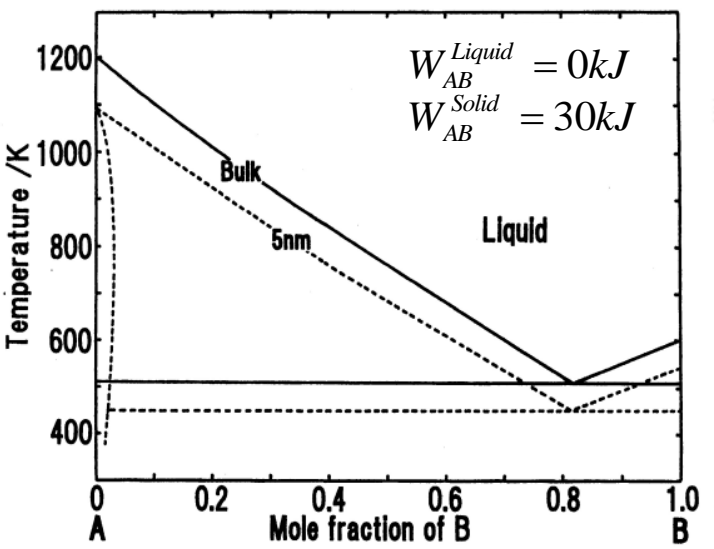

(d)

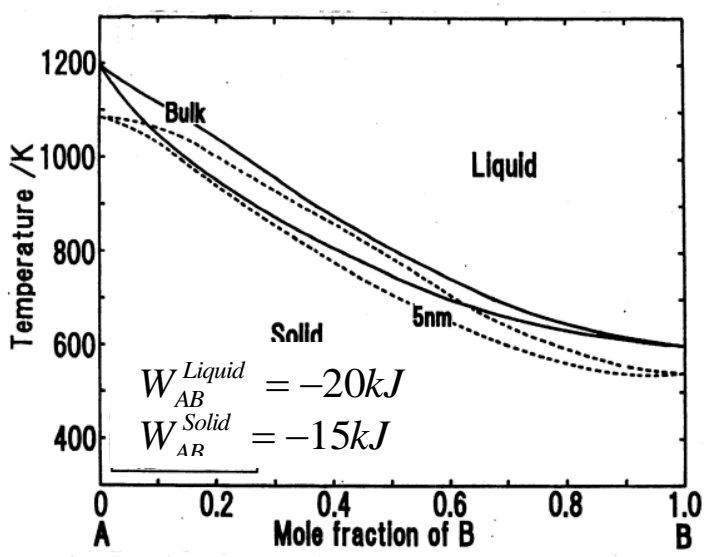

Fig.7. Phase diagrams nano-sized binary alloys for various $W_{A B}^{\text {Liquid }}$ and $W_{A B}^{\text {Solid }}$ values.

(a)

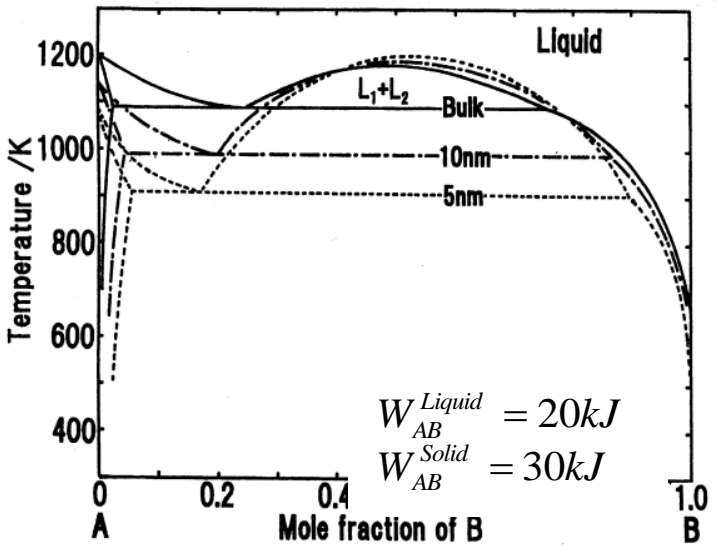

(b)

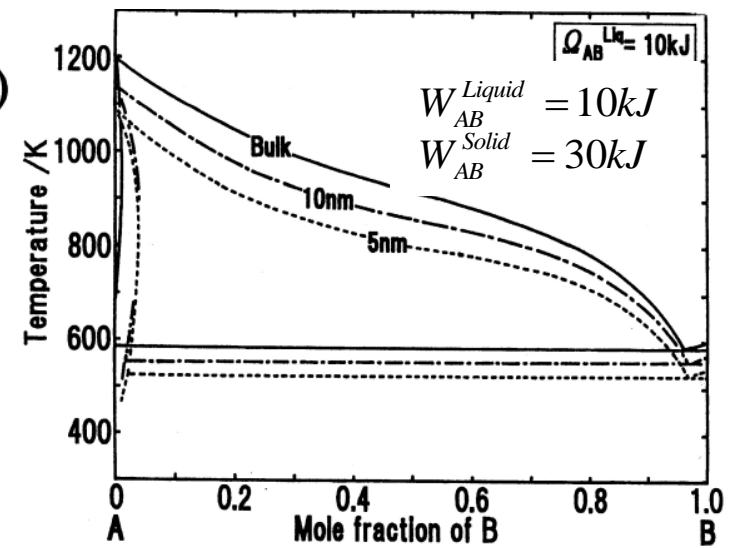

(c)

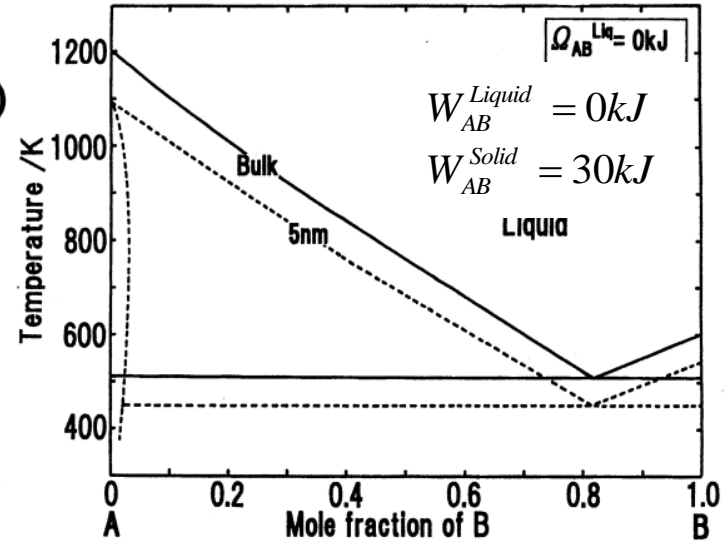

(d)

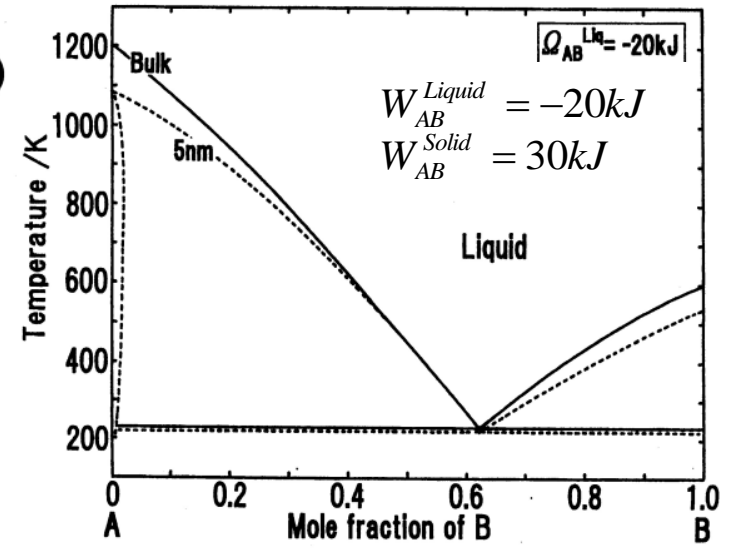

Fig.8. Phase diagrams nano-sized binary alloys for a fixed $W_{A B}^{\text {Solid }}$.

Figure 7(a) indicates the phase diagrams for the ideal solutions in both solid and liquid phases, in other words, $W_{\mathrm{AB}}{ }^{\mathrm{Liq}}=W_{\mathrm{AB}}{ }^{\mathrm{Sol}}=0$. When $W_{\mathrm{AB}}{ }^{\text {Sol }}$ increases from 0 to $30 \mathrm{~kJ}$ with $W_{\mathrm{AB}}{ }^{\text {Liq }}=0$, the phase 
diagrams change as shown in Figs. 7(b) and (c). Figure 7 (d) shows the phase diagrams for $W_{\mathrm{AB}}{ }^{\mathrm{Liq}}=$ $-20 \mathrm{~kJ}$ and $W_{\mathrm{AB}}{ }^{\text {Sol }}=-15 \mathrm{~kJ}$ as an example for $W_{\mathrm{AB}}^{\mathrm{Liq}}<0$ and $W_{\mathrm{AB}}{ }^{\text {Sol }}<0$. When $W_{\mathrm{AB}}$ Sol is fixed to be $30 \mathrm{~kJ}$ and $W_{\mathrm{AB}}^{\mathrm{Liq}}$ changes from -20 to $+20 \mathrm{~kJ}$, the phase diagrams are obtained as shown in Figs.8(a)-(d). As can be seen in Figs.7 and 8, when the interaction parameters are $W_{\mathrm{AB}}{ }^{\mathrm{Liq}}>0$ and $W_{\mathrm{AB}}{ }^{\mathrm{Sol}}>0$, the effect of the particle size on the phase diagrams is remarkable. As described above, the liquid or solid alloys indicate the large downward curvature of the composition dependence of the surface tension in the conditions of $W_{\mathrm{AB}}{ }^{\mathrm{Liq}}>0$ and $W_{\mathrm{AB}}{ }^{\text {Sol }}>0$. These composition dependence of the surface tension affect the contribution of $\Delta G^{\text {Surface, } \mathrm{P}}$ to $\Delta G^{\text {Total, } \mathrm{P}}$. Especially, when $W_{\mathrm{AB}}{ }^{\text {Sol }}>0$, the solid solutions do not appear in some of the phase diagrams of the bulk as shown in Figs.7(c), 8(c) and 8(d). However, when the particle size decreases, the contribution of $\Delta G^{\text {Surface,Sol }}$ to $\Delta G^{\text {Total,Sol }}$ in the solid phase can not be ignored. Consequently, as shown in Figs. 7 and 8, the solid solution appears in the small particle systems even when the bulk phase diagrams do not show the solid solutions. In addition, the solid solution region is enlarged as the size of the particle becomes smaller.

As described above, the phase diagrams of binary alloys in the small particle systems can be evaluated from the thermodynamic information usually stored in some databases, although the following rough approximations have been used in the present work:

1) The mass balance of atoms between the bulk and the surface are not considered though the surface segregation occurs in alloys.

2) The effects of crystal faces on the surface properties of solid phases are ignored.

4) The temperature dependence of the surface tension of pure solid phase is assumed to be the same as that of pure liquid phase.

\section{Comparison of Calculated Results on Nano-sized Phase Diagram with Experimental Observation of Melting Behavior in Binary Alloy}

As one of the examples for the comparison of calculated results on nano-sized phase diagrams with experimental obsevations, Figs.9 and 10 shows the melting behabior of Bi-Sn binary alloy small droplet and the phase diagram of Bi-Sn system for the bulk and nano-sized particle, which was conducted by Lee et al. [28].

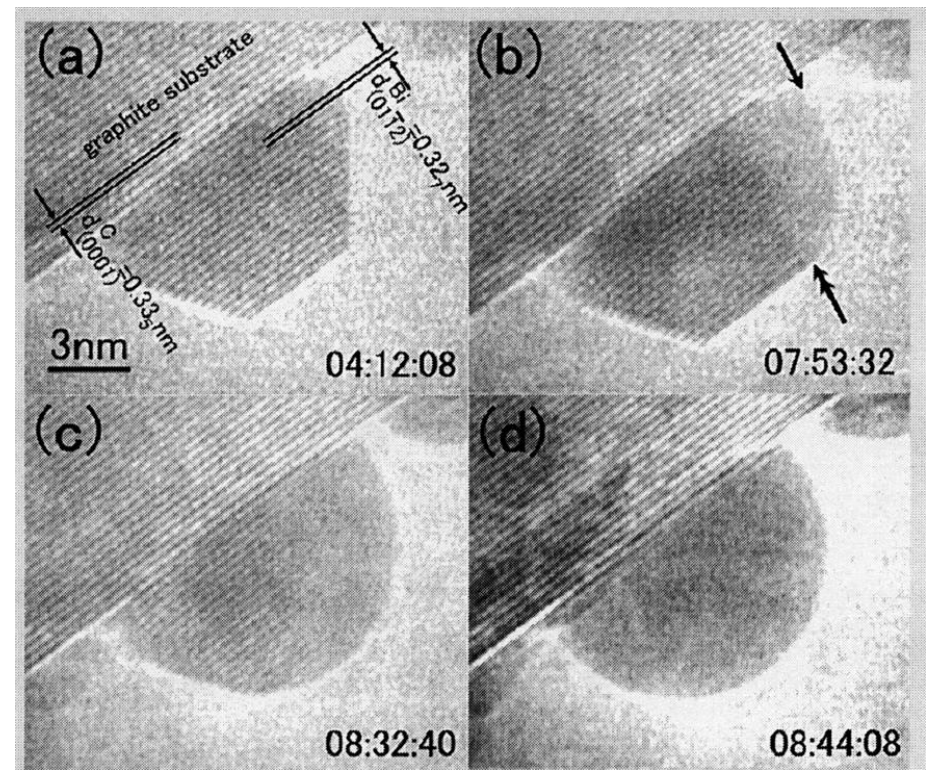

Fig.9. Observation for melting behabior of Bi-Sn binary alloy in a nano-sized droplet at $80^{\circ} \mathrm{C}(353 \mathrm{~K})$. [28] 


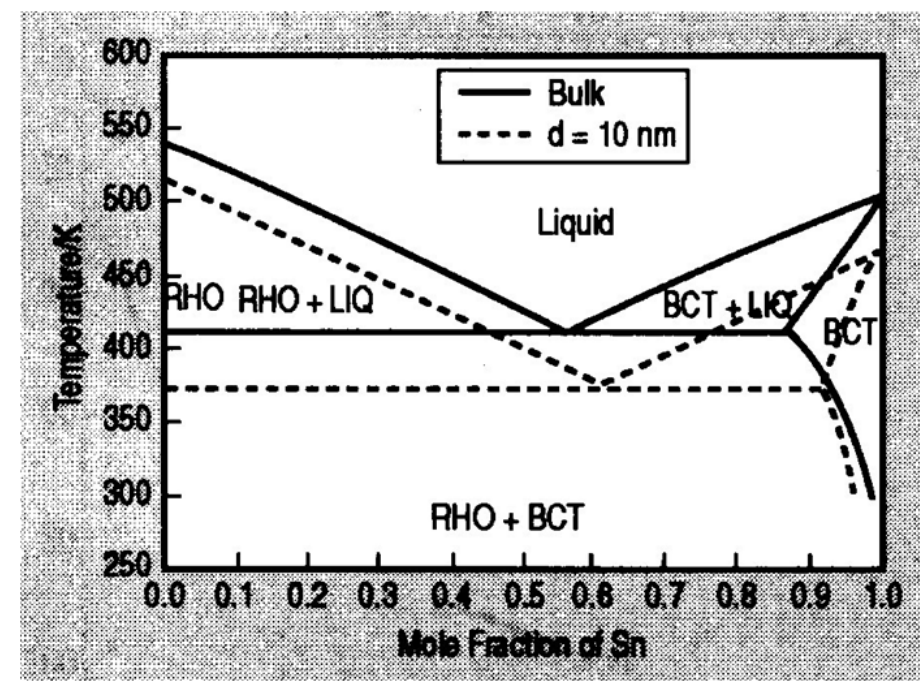

Fig.10. Calculated results on the phase diagram in Bi-Sn binary alloy for bulk and nano-sized particle. [28]

In the experiment, firstly pure $\mathrm{Bi}$ was vaporized in TEM chamber at $80^{\circ} \mathrm{C}(353 \mathrm{~K})$, and nano-sized pure solid Bi particle was deposited on graphite substrate as shown in Fig.9(a). Then, Pure Sn was vaporized and the $\mathrm{Sn}$ vapor penetrated into $\mathrm{Bi}$ nano-sized particle to make liquid alloy phase coexisted with pure Bi as indicated in Fig.9(b) and (c). In these figures, the interface between soid Bi and liquid phases was observed, and finally liquid alloy was formed completely as shown in Fig.9(d).

When we compare the above melting behavior of Bi-Sn alloy in Fig.9 with the phase diagram in Fig.10, firstly pure solid Bi existed, and then solid Bi was coexisted with liquid alloy phase according to the increase of Sn content. Finally, the composition of the alloy reached eutectic point to make liquid nano-sized droplet. Bi-Sn alloy does not make liquid phase at $80^{\circ} \mathrm{C}(353 \mathrm{~K})$ in the bulk size as shown in the phase disgram in Fig.10, but in the nano-sized particle, liquid phase may exist as suggested in the calculated result in Fig.10 and it was demonstraed as indicated in Fig.9. The detail of the above experimental procedure has been described in Refs. [28, 58,59]. J-G. Lee and H. Mori have carried out many observations on nano-particle phase transformation. The information on the matter can be obtained in the references quoted in Refs. [28,58,59].

\section{Problems in Thermodynamics of Small Particle Systems.}

As shown in Fig.1, the calculated result of the dependence of the melting point of Au on the particle size is larger than that of the experimental results at around $r<5 \mathrm{~nm}$. Various discussions on this difference have been reported so far as described above. In the present section, we discuss the above issue from a little bit different point of view.

\section{Effect of the Surface Tension on the Calculated Result on the Melting Point of Nano-sized Au particle.}

In Fig.1, we calculated the melting point of Au by using the data on the surface tension of the bulk liquid and solid Au reported in Ref. [60]. Since it is relatively easy to measure the surface tension of pure liquid $\mathrm{Au}$, which is not oxidized in the high temperature, a lot of experimental results of the surface tension of liquid Au were reported so far. The uncertainty of the experimental results is not so small even for pure Au. In addition, it is quite difficult to measure the precise value on the surface tension of pure solid metals. When the value of the surface tensions of liquid and solid Au are changed in Eq.(4), the melting point of pure Au with the radius rsmay shift. When we discuss, therefore, the difference of the calculated melting point of the nano-sized particle from the 
experimental data, we should consider the reliability of the data used in the above thermodynamic evaluations in addition to the criteria.

\section{Effect of the Surface Melting on the Calculated Result on the Melting Point of Nano-sized Au Particle.}

The surface melting has been known well in the bulk metals. In this phenomenon, the thin layers near the surface of metals are melted below the melting points of the bulk. For example, Kojima and Susa [61] investigated the surface melting of pure $\mathrm{Cu}$ by using MD method. They reported the surface melting occurs at $900 \mathrm{~K}$ in the face [111] although the bulk $\mathrm{Cu}$ melts at $1356 \mathrm{~K}$. The reason of the surface melting is supposed that the binding of atoms near the surface is weaker than that in the bulk. Therefore, in the nano-sized particles, of which surface area per unit volume is larger than that of the bulk systems, the surface phenomenon may occur more remarkably than the bulk system.

When we consider the effect of the surface melting on the fusion of nano particles, we should use smaller value of the heat of fusion than that of the bulk. However, we do not have any idea on how much the heat of fusion should be reduced in the evaluation of the properties in the nano-particles. Then, we evaluated the heat of fusion of Au to satisfy the calculated value of the melting point in Eq.(4) with the experimental data in Fig.1. Fig.11 shows the change in the heat of fusion of Au with the radius $r$ [62]. As shown in this figure, the heat of fusion decreases with decreasing the radius $r$, which means that the bonding between atoms are weakened in small particle size as decreasing the particles size. When we investigate the thermodynamic evaluation of the melting point of the nano-sized particles more precisely, we should consider the effect of the surface melting on those small particles.

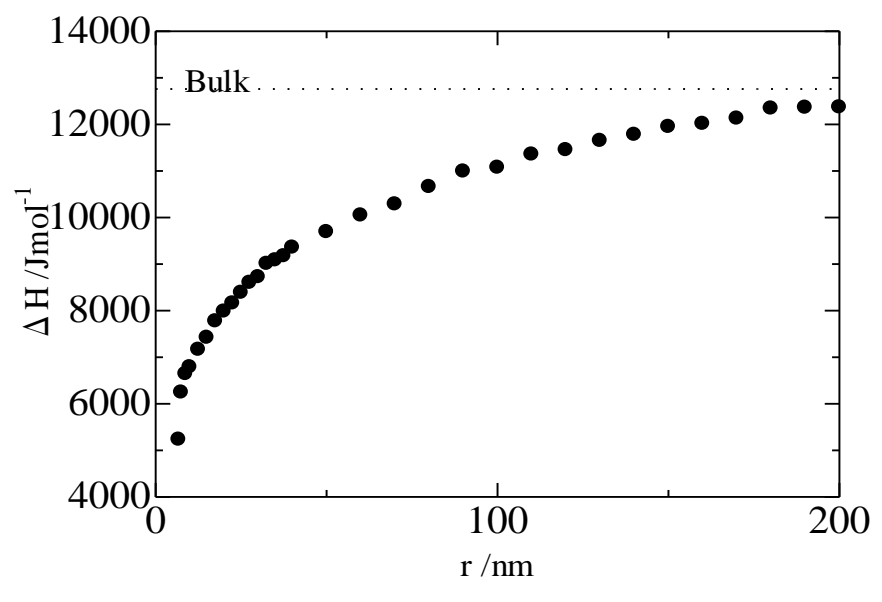

Fig.11. Calcularted results on change in the heat of fusion of $\mathrm{Au}$ with radius of a particle.

\section{Concluding Remarks.}

In the present paper, the author has described some fundamental procedures to evaluate the solidliquid phase relations of nano-sized particles in binary alloys from the calculation of the surface properties as well as the phase equilibira on the basis of thermodynamic databases, which are usually used for the calculation of phase diagrams of the bulk materials. In order to obtain quantitatively precise values of the melting points and liquidus temperatures in alloys, we should carry out further investigation on as follows:

1) More detail discussion on the criteria on the melting of nano-sized particles. 
2) The reliability of the data used for the evaluation of the melting phenomena of the nano-sized particles, especially the surface energies of liquid and solid alloys.

3) The change in the bonding of atoms near the surface from that of the bulk in relation to the surface melting phenomena.

We can, however, evaluate the phase equilibria of small particles qualitatively from the macroscopic thermodynamic point of view as described in the present paper. Thus, the authors wish that a lot of attentions should be paid to the application of thermodynamic databases to the calculation of the phase diagrams of the nano-sized particles, of which information will be demanded increasingly in the near future.

\section{Acknowledgement}

The author thanks Professor Joonho Lee in Korea University for his useful discussion in this study.

\section{References}

[1] C.W. Bale and G. Eriksson : Canad. Metall. Quart. Vol.29 (1990), p.105.

[2] T. Nishizawa : Mater. Trans. JIM Vol.33 (1992), p.713.

[3] T. Tanaka and T. Iida : Steel Research Vol.65 (1994), p.21.

[4] T. Tanaka, K. Hack, T. Iida and S. Hara : Z. Metallkd. Vol.87 (1996), p.380.

[5] T. Tanaka, S. Hara, M. Ogawa and T. Ueda : Z. Metallkd. Vol.89 (1998), p.368.

[6] T. Tanaka, S. Hara, M. Ogawa and T. Ueda : Molten Salt Forum Vol.5-6 (1998), p. 213.

[7] T. Tanaka, S. Hara and T. Ueda: Proc. 11th Intern. Symp. on Molten Salts, San Diego, ECS,USA, ed. P.C. Trulove, H.C. De Long, G.R. Stafford, S.Deki, (1998), p.645.

[8] T. Tanaka, K. Hack and S. Hara : MRS Bulletin Vol.24 (1999), p.45.

[9] T. Tanaka and S. Hara : Electrochemistry Vol.67 (1999), p.573.

[10] T. Tanaka and S. Hara : Z. Metallkd. Vol.90 (1999), p.348.

[11] T. Ueda, T. Tanaka and S. Hara : Z. Metallkd. Vol.90 (1999), p.342.

[12] T. Tanaka, K. Hack and S. Hara : CALPHAD Vol.24 (2001), p.465.

[13] T. Tanaka, T. Kitamura and I. Back : ISIJ International Vol.46 (2006), p.400.

[14] R. Pajarre, P. Koukkari, T. Tanaka and J. Lee : CALPHAD Vol.30 (2006), p.196.

[15] M. Nakamoto, A. Kiyose, T. Tanaka, L. Holappa and M. Hamalainen : ISIJ International Vol.47 (2007), p.38.

[16] M. Nakamoto, T. Tanaka, L. Holappa and M. Hamalainen : ISIJ International, Vol.47 (2007), p.211.

[17] M. Hanao, T. Tanaka, M. Kawamoto and K. Takatani : ISIJ International Vol.47 (2007), p.935.

[18] P. Pawlow : Z. Phys. Chem. Vol.65 (1909), p 1.

[19] M. Takagi : J. Phys. Soc. Jpn Vol.9 (1954), p.359.

[20] B.C, Allen and W.D. Kingery : Trans. Metall. Sco. AIME Vol.215 (1959), p.30.

[21] C.R.M Wronski : Brit. J. Appl. Phys. Vol.18 (1967), p.1731.

[22] Ph. Buffat, J-P. Borel : Phys. Rev. 13 (1976) 2287-2298.

[23] P.R. Couchman and W.A. Jesser : Nature 269 (1977) 481-483. 
[24] G.L Allen, R.A. Bayles, W.W. Gile and W.A. Jesser : Thin Solid Films 144 (1986) 297-308.

[25] T. Tanaka and S. Hara : Z. Metallkde. Vol.92 (2001), p.467.

[26] T. Tanaka and S. Hara : Z. Metallkunde, Vol.92 (2001), p.1236.

[27] T. Tanaka, J. Lee and N. Hirai : Chemical Thermodynamics for Industry, edited by T.M. Letcher, the Royal Society of Chemistry, Cambridge, UK, (2004), p.207.

[28] J-G. Lee, J-H. Lee, T. Tanaka, H. Mori and K. Penttila JOM, March (2005), p.56.

[29] J-H. Lee, M. Nakamoto and T. Tanaka : J. Materials Science, Vol.40 (2005), p.2167.

[30] J-H. Lee, J. Park, T. Tanaka : CALPHAD, Vol.33 (2009), p.377.

[31] J.P. Hajra and S. Acharya : J. Nanoscience and nanotechnology Vol. 4 (2004), p.899.

[32] C.J. Coombes : J. Phys. F Vol.2 (1972), p.441.

[33] J.R. Sambles : Proc. Roy. Soc. Lond. A. Vol.324 (1971), p.339.

[34] J.P. Borel : Surf. Sci., 106 (1981) , 1-9.

[35] H. Reiss and I.B. Wilson : J. Colloid Sci. Vol.3 (1948), p.551.

[36] K.J. Hanszen : Z. Phys. Vol.157 (1960), p.523.

[37] E. Rie : Z. Physik. Chem. Vol.104 (1923), p.354.

[38] J. Ross and R.P. Andres : Surf. Sci., 106 (1981), 11-17.

[39] P.R. Couchman and C.L. Ryan : Phil. Mag., A37 (1978), 369.

[40] R.A. Swalin : Thermodynamics of Solids, John Wiley, New York (1962).

[41] J. Niemelae, G. Effenberg, K. Hack and P.J. Spencer : CALPHAD 10 (1986) 77-89.

[42] A.T. Dinsdale : CALPHAD 15 (1991) 317-425.

[43] F.H. Hays, H.L. Lukas, G. Effenberg and G. Petzow. : Z. Metallkd. 77 (1986) 749-754.

[44] P.J. Spencer : Private communication (2000)

[45] L.E. Murr : Interfacial Phenomena in Metals and Alloys, Addison-Wesley, London (1975).

[46] V.K. Kumikov and Kh.B. Khokonov : J. Appl. Phys. 54 (1983) 1346-1350.

[47] T. Iida and R.I.L. Guthrie : "The Physical Properties of Liquid Metals", Clarendon Press, Oxford, (1988), p.71, p.132.

[48] L.J. Wittenberg and R. DeWitt : J. Chem. Phys. 56 (1972) 4526-4533.

[49] J.A.V. Butler: Proc. Roy. Soc. Vol.A135 (1932), p.348.

[50] R. Speiser, D.R. Poirier and K. Yeum : Scripta Metall. Vol. 21 (1987), p. 687.

[51] K.S. Yeum, R. Speiser and D.R. Poirier : Metall. Trans. $20 B$ (1989) 693-703.

[52] G. Metzger : Z. Phys. Chem. Vol.211 (1959), p.1.

[53] J.C. Joud, N. Eustathopoulos and A.Bricard ; Desre, P. : J. Chim. Phys. 70 (1970) 1290-1294.

[54] R.C. Tolman : J. Chim.Phys. Vol.17 (1949), p.333.

[55] I.D. Morokhov : Izv. Akad. Nauk SSSR Metall. No.6 (1979) 159-161.

[56] N.T. Gladkikh, L.K. Grigoreva and S.V. Dukarov : Sov. Phys. Solid State 31 (1989) 728-733.

[57] A.D. Pelton ; Thompson, W.T. : Prog. Solid State Chem., 10 (1975) 119.

[58] J-G. Lee, J-H. Lee, T. Tanaka and H. Mori : Physical Review Letters, vol.96, 075504 
(2006), p.1.

[59] J-G. Lee, J-H. Lee, T. Tanaka and H. Mori : Nanotechnology, Vol. 20 (2009), 475706.

[60] J.M. Howe : Interfaces in Materials, John Wiley \& Sons, Inc., New York, (1997).

[61] R. Kojima and M. Susa : High Temp. High Press., 34 (2002), p.639.

[62] J-H.Lee : Private communication. 